\title{
Clinical Profile and Outcomes of Patients Undergoing Percutaneous Coronary Intervention: A 5 Year Experience
}

\author{
Navaraj Paudel' \\ ${ }^{1}$ Associate Professor and Consultant Cardiologist, Department of Internal Medicine, Cardiology Unit, Manipal College of \\ Medical Sciences, Pokhara, Nepal.
}

\section{ABSTRACT \\ Introduction}

Ischemic Heart Disease is the leading cause of mortality and morbidity in the world. Among the ACS, the mortality rate is highest for ST Elevation Myocardial Infarction. Primary Percutaneous Coronary Intervention has emerged as the therapy of choice with better outcomes. In this study we have studied the profile and outcomes of patients with coronary artery diseases in our part of world.

\section{Methods}

A retrospective, cross-sectional study was done in the department of medicine (cardiology unit) of Manipal Teaching Hospital, Pokhara. All the cases undergone PCI were taken and analyzed accordingly for the clinical profile and outcomes within the hospital stay from April 2015 to March 2020 (5 years). The data was collected in a preformed proforma and was entered in excel sheet and analyzed using SPSS software version 21. Various statistical tools were used accordingly and $\mathrm{p}$ values were considered significant at a predetermined alpha level of $5 \%$.

\section{Results}

The total number of procedures done for coronary arteries in Cath lab for 5 years were 2602 of which 2014 were angiographies and 588 were percutaneous coronary interventions/ angioplasties. The male-female ratio was 2.01. Out of 588 angioplasties, 326 were primary. Fifty-five percent of patients undergone angioplasties were age more than 65 . Twelve percent of patients with acute coronary syndromes were young (less than 40 years of age). Smoking was the commonest risk factor (71\%) followed by hypertension (52\%), Dyslipidemia (50\%) and Diabetes (18\%). Anterior wall myocardial infarction involving left anterior descending artery was the commonest presentation. Right radial artery was the preferred route for procedure $(69 \%)$ followed by right femoral artery (22\%). Fourteen patients (2.3\% of total, $5.0 \%$ in Primary) died. Most of the deaths were patients having anterior wall STEMI involving LAD with high TIMI scores (>6) (P: 0.0003).

\section{Conclusions}

Ischemic heart disease is the commonest cause of mortality worldwide. In our study population, there was male preponderance. ST Elevated MI was the most common presentation of acute coronary syndrome and almost $85 \%$ cases posted for primary angioplasty. LAD was the most common artery causing IHD and also was significantly associated with high TIMI score and mortality. ACS in young is alarmingly increasing in this part of world probably associated with increased rates of smoking in younger population.

Keywords: Ischemic Heart Disease, Percutaneous Coronary Intervention, Risk Factors, Outcome

Correspondence: Dr. Navaraj Paudel, Department of Internal Medicine, Cardiology Unit, Manipal College of Medical Sciences, Phulbari-1 1, Pokhara-33700, Nepal. Email: drnavarajdm@gmail.com. Phone: +977-9856085037. 


\section{INTRODUCTION}

Ischemic Heart Disease (IHD) is the leading cause of mortality and morbidity in the world. ${ }^{1}$ In Nepal, IHD was the number 1 killer in year 2017 and will most probably remain so for at least few years to come. ${ }^{2}$ IHD may present as stable IHD or Acute coronary syndromes (ACS). Among the ACS, the mortality rate is highest for ST Elevation Myocardial Infarction (STEMI). ${ }^{3}$

Primary Percutaneous Coronary Intervention (PPCI) has emerged as the therapy of choice in STEMI and selected cases of Non-ST Elevation Myocardial Infarction (NSTEMI). ${ }^{4-8}$ As Percutaneous coronary intervention (PCI) enters its fourth decade, it is now the most commonly performed revascularization therapy worldwide. With the development of drug eluting stents, clinical outcomes have improved significantly.

The proportion of ACS types varies across various studies with decrease in the STEMI as compared to NSTEMI owing to development of more sensitive markers of myocardial injury.

${ }^{9}$ Roughly two-thirds of patients with MI have NSTEMI; the rest have STEMI. ${ }^{10}$ Meanwhile, we have limited data on the nature and distribution of ACS in Nepal ${ }^{11-16}$ and moreover no data is available in this part of country.

Manipal College of Medical Sciences- Manipal Teaching Hospital was the only hospital having cathlab facility in the province no 4 of Nepal serving almost 25 lakhs population till 2021 April. With the facility it has been involved in cardiac interventions since 2015. Here we have tried to look at the profiles and outcomes of all the patients undergone PCI since its establishment in Manipal, Pokhara.

\section{METHODS}

A retrospective, cross-sectional study was done in the department of medicine (cardiology unit) of Manipal Teaching Hospital, Pokhara. All the cases undergone PCI were taken and analysed accordingly for the clinical profile and outcomes within the hospital stay from April 2015 to March 2020 (5 years). Patients who underwent medical management for ACS or critical coronary artery disease (CAD) were excluded. And also those who does not provide written consent were also excluded.

All patients presenting with symptoms suggestive of angina and ACS who were counseled about the treatment modalities in emergency (ER) with clear outcome benefits of PCI over medical management were taken for PCI if indicated. Those who did not give written informed consent for PCI or chose medical management were excluded. ACS patients those patients presenting late or thrombolysed were taken for elective PCI after hospital admission accordingly.

Usual hospital protocol for the procedure was followed for the PCI. After the procedure, patient was transferred to CCU and managed. Complications were assessed till hospital stay including mortality. Medical records were reviewed which included medical history, physical examination, age, gender, CAD risk factor profile, smoking history, lipid profile, fasting blood sugar, HbA1C levels, ECG, echocardiography and coronary angiography. Dyslipidemia was defined as the presence of any of the following: patients on lipid lowering drugs or total cholesterol $>240 \mathrm{mg} / \mathrm{dl}$, triglycerides (TG) >150 mg/dl, low-density lipoprotein $>130 \mathrm{mg} / \mathrm{dl}$, and high-density lipoproteins (HDL) $<40 \mathrm{mg} / \mathrm{dl}$ in male. ${ }^{17}$ Diabetes mellitus was defined as fasting blood sugar level of $126 \mathrm{mg} / \mathrm{dl}$ (7.0 $\mathrm{mmol} / \mathrm{L}$ ) or $\mathrm{HbA} 1 \mathrm{C}$ level $>6.5$ or if patient was on oral hypoglycemic agents. ${ }^{18}$ Hypertension was defined as systolic blood pressure $>140$ 
and/or diastolic $>90 \mathrm{mmHg}$ and/or on antihypertensive treatment. ${ }^{19}$ Positive family history was considered if first degree relatives had CAD before the age of 55 years in men and 65 years in women. ${ }^{17}$ Significant CAD was defined as a diameter stenosis $>50 \%$ in each major epicardial artery. Normal vessels were defined as the complete absence of any disease in the left main coronary artery (LMCA), left anterior descending (LAD), right coronary artery (RCA), and left circumflex (LCX) as well as in their main branches (diagonal, obtuse marginal, ramus intermedius, posterior descending artery, and posterolateral branch). Patients were classified as having single-vessel disease (SVD), double vessel disease (DVD) or triple vessel disease (TVD) accordingly.

The data was collected in a preformed proforma and was entered in excel sheet and analyzed using SPSS software version 21. Percentage, mean value were calculated and Pearson's correlation coefficient, chi square test, t-tests, odds ratio etc were calculated wherever required and $p$ values were considered significant at a predetermined alpha level of $5 \%$.

\section{RESULTS}

The total number of procedures done for coronary arteries in Cath lab for 5 years were 2602 of which 2014 were angiographies and 588 were angioplasties. The following table shows the number of procedures done in Manipal Teaching Hospital as of 2021 April (Table 1).

\begin{tabular}{|l|l|c|c|c|}
\hline Procedures & CAG & \multicolumn{2}{|c|}{ PCI (n=588) } & Total \\
\hline \multirow{2}{*}{ Numbers } & & Elective & Primary & \\
\cline { 3 - 4 } & 2014 & 312 & 276 & 2602 \\
\hline
\end{tabular}

male and 195 female patients underwent PCI with M: F ratio of 2.01 .
Table 2. Acute coronary syndrome according to age

\begin{tabular}{|c|c|c|}
\hline Age (in yrs) & Number of patients & $\%$ of patients \\
\hline$\leq 40$ & 71 & 12.07 \\
\hline $41-64$ & 190 & 32.31 \\
\hline$\geq 65$ & 327 & 55.61 \\
\hline
\end{tabular}

$12 \%$ of patients with ACS were below the age of 40 years (considered as young ACS).

Table 3. Risk factor analysis in case of ACS $(n=588)$

\begin{tabular}{|l|c|c|}
\hline \multicolumn{1}{|c|}{ Risk Factors } & $\begin{array}{c}\text { Number of } \\
\text { patients }\end{array}$ & $\begin{array}{c}\% \text { of } \\
\text { patients }\end{array}$ \\
\hline Smoking & 417 & 71 \\
\hline Hypertension & 309 & 52.5 \\
\hline Dyslipidemia & 297 & 50.5 \\
\hline Diabetes Mellitus & 108 & 18.3 \\
\hline Obesity (BMI $\geq 25 \mathrm{Kg} / \mathrm{m} 2)$ & 99 & 16.8 \\
\hline
\end{tabular}

The most common risk factor in patients with ACS was smoking $(71 \%)$ followed by hypertension (52\%), Dyslipidemia (50\%), Diabetes $(18 \%)$ and Obesity (16.8\%).

Table 4 The arteries where the $\mathrm{PCl}$ were done:

\begin{tabular}{|l|c|c|c|}
\hline PCI performed & LAD & RCA & LCX \\
\hline Elective & 155 & 88 & 69 \\
\hline Primary & 105 & 98 & 73 \\
\hline
\end{tabular}

\begin{tabular}{|c|c|c|c|c|}
\hline \multicolumn{2}{|c|}{ Table 5. Primary PCI performed for: } \\
\hline ACS type & \multicolumn{3}{|c|}{ STEMI (n=223) } & $\begin{array}{r}\text { Unstable } \\
\text { Angina/ } \\
\text { NSTEMI } \\
\text { (n=53) }\end{array}$ \\
\hline Numbers & $\begin{array}{c}\text { Anterior } \\
\text { wall }\end{array}$ & $\begin{array}{c}\text { Inferior } \\
\text { wall }\end{array}$ & $\begin{array}{c}\text { Pure } \\
\text { posterior } \\
\text { wall }\end{array}$ & \multirow{2}{*}{53} \\
\cline { 2 - 4 } & 105 & 103 & 15 & \\
\cline { 2 - 4 } & 105 & &
\end{tabular}

Most of the procedures were performed via right radial route (69.21\%). Following (Table 6) shows the different approaches/ routes used while performing PCI. 


\begin{tabular}{|c|c|c|c|c|c|c|}
\hline \multirow{4}{*}{ Access } & \multicolumn{2}{|c|}{ Radial } & Ulnar (Right) & \multicolumn{2}{c|}{ Femoral } & \multirow{2}{*}{ Switch over to femoral from radial/ulnar } \\
\cline { 2 - 3 } & Right & Left & & Right & Left & \multirow{2}{*}{2} \\
\cline { 2 - 3 } \cline { 5 - 6 } & 407 & 08 & 02 & 131 & 12 & \\
\hline
\end{tabular}

Table 7. Outcomes of PCl (Note: No patients with elective PCI had mortality):

\begin{tabular}{|l|l|l|l|l|}
\hline Outcome & Discharged & In hospital mortality & Left against medical advices & Referred \\
\hline Elective & 310 & 00 & 02 & 00 \\
\hline Primary & 251 & 14 & 07 & 04 \\
\hline
\end{tabular}

Total fourteen patients $(2.3 \%$ of total, $5 \%$ in primary) died during or shortly after the procedure. Most of the deaths were patients having anterior wall STEMI with high TIMI scores. These patients died within 24 hours post procedure (Table 7). procedures done for coronary arteries were 2602 of which 2014 were angiographies and 588 were angioplasties. 393 male and 195 female patients underwent PCI with M: F ratio of 2.01. Although slightly lower, similar results were seen in INTERHEART study and it's South Asian Cohort

Table 8. Mortality in primary $\mathrm{PCl}$ (Total 14)

\begin{tabular}{|c|c|c|c|c|}
\hline \multirow{4}{*}{ ACS type } & \multirow{2}{*}{ STEMI } & Anterior wall (LAD) & Inferior wall (RCA/LCX) & Posterior (LCX) \\
\cline { 3 - 5 } & & 09 & 03 & 01 \\
\cline { 3 - 5 } & & & 01 & 01 \\
\cline { 2 - 5 } & UA/NSTEMI & & 01 & \\
\hline
\end{tabular}

We further analyzed the nine patients who died were anterior wall STEMI (105 patients were having anterior wall involving LAD), very sick patients with high TIMI scores and most of them were having cardiogenic shock (Table 9).
(Overall Male 76\%). ${ }^{20}$ Maximum patients were of age group of more than $65 y$ rs. Around $12 \%$ of patients were considered as young ACS (Table 2 ). The patients with young ACS comprises from $8-13 \%$ around the globe including Nepal. ${ }^{10-16}$

\begin{tabular}{|l|l|l|c|c|c|}
\hline \multirow{2}{*}{$\begin{array}{c}\text { TIMI Score } \\
\text { (Anterior wall STEMI) }\end{array}$} & \multicolumn{2}{|c|}{ Mortality } & Odds ratio & $\mathbf{9 5 \%}$ Confidence interval & P value \\
\cline { 1 - 5 } & Yes & No & & & \\
\cline { 1 - 3 } Yes & 08 & 12 & 56.00 & $6.42-488.06$ & 0.0003 \\
\hline
\end{tabular}

There is significant $(\mathrm{P}=0.0003)$ mortality in patients with Anterior wall STEMI with TIMI score more than 6 .

\section{DISCUSSION}

Manipal Teaching Hospital started its functioning cathlab in April 2015. By far, the total number of
The most common risk factor in patients with ACS was smoking (71\%). Smoking was seen as commonest risk factor out of the other conventional risk factors in other studies too. ${ }^{14-}$ ${ }^{16,}{ }^{21}$ This was followed by hypertension (52\%), Dyslipidemia (50\%), Diabetes (18\%) and Obesity $(16.8 \%)$. The prevalence of hypertension in the 
South Asian Cohort of INTERHEART Study 20 was $31.1 \%$ which is much lower than our study. However, studies done in Pakistan ${ }^{21}$ and India ${ }^{22}$ showed $55 \%$ and $48 \%$ respectively which is similar to our study. We had patients with higher dyslipidemics than other studies like INTERHEART South Asian Cohort ${ }^{20}$ and a study form Bangladesh. ${ }^{23}$ Diabetes is another important risk factor which was found in $18 \%$ of study population. This was similar as shown by INTERHEART study ${ }^{20}$ in South Asian Cohort.

The most common artery affected in our study and undergone PCI was left anterior descending (LAD) followed by right coronary artery (RCA) and left circumflex artery (LCX) in our study. This was similar in a study done in western countries. ${ }^{24}$ Primary PCI was done for STEMI of any types (most commonly for anterior wall) in almost $85 \%$ of cases. This is a usual scenario in various other countries including other centers of Nepal. ${ }^{11-13,22-24}$

Radial route (right radial artery) was the most preferred route to perform PCI (both primary and elective) in our study followed by right femoral artery. With the advancement of the techniques and experience, this is now becoming popular all over the world..$^{25,26}$

Total fourteen patients $(2.3 \%$ of total, $5 \%$ in Primary) died during or shortly after the procedure. All patients who died were in primary PCI group. No elective PCI patients died. TIMI score ${ }^{27}$ is frequently assessed for prediction of mortality in cases of ACS. Most of the deaths were patients having anterior wall STEMI with

\section{REFERENCES}

1. Cardiovascular diseases (CVDs) Fact sheet [Internet]. WHO. [Cited 2019 MARCH 3]. Available from cardiovascular-diseases(cvds). high TIMI scores. As showed in Tables 8 and 9 in our study, patients with anterior wall involving LAD with high TIMI scores (>6) have significant mortality (P: 0.0003) than other wall STEMI and TIMI scores 5 or less. These patients died within 24 hours post procedure (Table 5). It's a proven fact that higher the TIMI score, the higher is the mortality. ${ }^{27}$

Study Limitations: This is a retrospective study taken form hospital files. No follow up data was taken as this study was based only on inhospital records, hence mortality after hospital stay (30day/90day) could not be assessed.

\section{CONCLUSIONS}

The most common mortality worldwide is secondary to IHD. There have been substantial increase in IHD although there is decrease in cardiovascular disease mortality in developed countries. In our study population, there was male preponderance. STEMI was the most common presentation of ACS and almost $85 \%$ cases posted for primary PCI in cathlab. Smoking was the most common risk factor followed by hypertension, dyslipidemia and diabetes mellitus. LAD was the most common artery causing IHD and also was significantly associated with high TIMI score and mortality. ACS in young is alarmingly increasing in this part of world probably associated with increased rates of smoking in younger population. Nationwide primary and secondary prevention strategies should be vigorously pursued in order to reduce the risk factors.

2. Top ten causes of death, 2017 [Internet]. The Institute for Health Metrics and Evaluation (IHME).[Cited 2019 March 3] Available from

3. Aude Marceau, Jean-Michel Samson, 
Nathalie Laflamme, Stéphane Rinfret. Short and long-term mortality after stemi versus non-stemi: a systematic review and meta-analysis. Journal of the American College of CardiologyVolume 61, Issue 10 Supplement, March 2013. DOI: 10.1016/S0735-1097(13)60097-2 .

4. Fox KA, Poole-Wilson P, Clayton TC, et al. 5-year outcome of an interventional strategy in non-ST-elevation acute coronary syndrome: the British Heart Foundation RITA 3 randomised trial. Lancet. 2005; 366:914-920.

5. Cannon CP, Weintraub WS, Demopoulos LA, et al. TACTICS (Treat Angina with Aggrastat and Determine Cost of Therapy with an Invasive or Conservative Strategy)-Thrombolysis in Myocardial Infarction 18 Investigators. Comparison of early invasive and conservative strategies in patients with unstable coronary syndromes treated with the glycoprotein IIb/IIIa inhibitor tirofiban.N Engl J Med. 2001; 344:18791887.

6. Lagerqvist B, Husted S, Kontny F, et al. Fast Revascularisation during InStability in Coronary artery disease (FRISC-II) Investigators. 5-year outcomes in the FRISC-II randomised trial of an invasive versus a noninvasive strategy in nonST-elevation acute coronary syndrome: a follow-up study.Lancet. 2006; 368:9981004.

7. Fox KA, Clayton TC, Damman P, et al. FIR Collaboration. Long-term outcome of a routine versus selective invasive strategy in patients with nonST-segment elevation acute coronary syndrome a meta-analysis of individual patient data.J Am Coll Cardiol. 2010; 55:2435-2445.

8. Keeley EC, Boura JA, Grines CL. Primary angioplasty versus intravenous thrombolytic therapy for acute myocardial infarction: a quantitative review of 23 randomised trials. Lancet. 2003; 361:13.

9. Benjamin EJ, Blaha MJ, Chiuve SE et al. Heart disease and stroke statistics-2017 update. A report from American Heart Association. Circulation. 2017;135 (10):e146-e606. https://doi.org/10.1161/ CIR.0000000000000491.

10. (Lloyd-Jones D, Adams R, Carnethon $\mathrm{M}$, et al. American Heart Association Statistics Committee and Stroke Statistics Subcommittee Heart disease and stroke statistics-2009 update. a report from the American Heart Association Statistics Committee and Stroke Statistics Subcommittee [published correction appears in Circulation. 2009;119(3):e182] Circulation 2009 January27; 119(3):480486 Epub 2008 Dec 15. https://doi. org/10.1161/circulationaha.108.191259.

11. Shreshta NR, Basnet S, Bhandari R et al .Presentation and outcome of patients with acute coronary syndromes in eastern Nepal. Swiss Med Wkly. 2011 Apr 13;141:w13174. doi: 10.4414/ smw.2011.13174. eCollection 2011. https://doi.org/10.4414/smw.2011.13174

12. Gautam MP, Sogunuru G, Subramanyam $\mathrm{G}$, et al. Acute coronary syndrome in an intensive care unit of a tertiary care centre: the spectrum and coronary risk factors. J Nepal Med Assoc. 2013 Apr-Jun;52(190):316-21. https://doi. org/10.31729/jnma.1897 
13. Chhetri BK, Paudel MS, Dhungana SP et al. Clinical profile of patients with acute coronary syndrome in Lumbini Medical College and Teaching Hospital: A prospective study. Journal of Lumbini Medical College. Dec 30, 2013. https://doi. org/10.22502/jlmc.v1i1.3

14. Laudari S, Dhungel S, Dubey L et al. Acute coronary syndrome in the young Nepalese population with their angiographic characteristics. Journal of College of Medical Sciences-Nepal, Vol-13, No 2, Apr-June 017. https://doi.org/10.3126/ jcmsn.v13i2.17147.

15. Paudel N, Alurkar VM, Jha GS et al. Profile of acute coronary syndrome in young people: a hospital based observational study in western nepal. Birat journal of health sciences. vol.3/no.1/issue 5/ janapril 2018. https://doi.org/10.3126/bjhs. v3i1.19759

16. Shakya, A., Jha, S. C., Gajurel, R. M., Poudel, C. M., Sahi, R., Shrestha, H., Devkota, S., \& Thapa, S. (2019). Clinical characteristics, risk factors and angiographic profile of acute coronary syndrome patients in a tertiary care center of Nepal. Nepalese Heart Journal, 16(1), 27-32. https://doi. org/10.3126/njh.v16i1.23895.

17. Third Report of the National Cholesterol Education Program (NCEP) Expert Panel on Detection, Evaluation, and Treatment of High Blood Cholesterol in Adults (Adult Treatment Panel III) Executive Summary. National Cholesterol Education Program National Heart, Lung, and Blood Institute National Institutes of Health NIH Publication No. 01-3670 May 2001. https:// doi.org/10.1001/jama.285.19.2486.
18. American Diabetes Association. Diabetes Care 2018 Jan; 41(Supplement 1): S13-S27.

19. Thomas L, Schwenk, MD and Thomas L, et al. JAMA 2003 May 21. New Hypertension Guidelines: JNC 7.

20. Yusuf S, Hawken S, Ounpuu S, et al. Effect of potentially modifiable risk factors associated with myocardial infarction in 52 countries (the INTERHEART study): Case- controlstudy. Lancet 2004;364:937$952 . \quad$ https://doi.org/10.1016/S01406736(04)17018-9.

21. Maqbool H, Jafary, Abdus Samad, et al. Profile of Acute Myocardial Infarction in Pakistan. Pak J Med JulySeptember 2007. Vol. 23 No.4 485-489.

22. Kumar N, Sharma S, Mohan B, et al. Clinical and angiographic profile of patients presenting with first acute myocardial infarction in a tertiary care center in northern India. Indian Heart J. 2008 May-Jun;60(3):210-4.

23. Islam, A, Faruque, M, Chowdhury A, et al. Risk factor Analysis and Angiographic Profiles in First 228 Cases Undergone Coronary Angiography in Cardiac Cath Lab of Dhaka Medical College Hospital. Cardiovascular Journal, 3(2), 122-125. https://doi.org/10.3329/cardio.v3i2.9179.

24. Behshad Naghshtabrizi, Abbas Moradi, Jalaleddin Amiri, Sepide Aarabi, Zahra Sanaei. An Evaluation of the Numbers and Locations of Coronary Artery Disease with Some of the Major Atherosclerotic Risk Factors in Patients with Coronary Artery Disease. J Clin Diagn Res. 2017 Aug; 11(8): OC21-OC24. doi: 10.7860/ JCDR/2017/29104.10460. 
25. Pandey R., Adhikari C., Bhatt $Y$ and Bhattarai M. Percutaneous Transradial Approach for the Coronary Angioplasty at a Tertiary Cardiac Centre in Nepal. Journal of Nepal Health Research Council, 2017:18(3):366-372. DOI:10.33314/jnhrc. v18i3.2587.

26. Vicens Marti, Salvatore Brugaletta, Joan García-Picart, et al. Radial versus femoral access for angioplasty of ST-segment elevation acute myocardial infarction with second-generation drug-eluting stents. Rev
Esp Cardiol (Engl Ed). 2015 Jan;68(1):4753. DOI: 10.1016/j.rec.2014.02.024.

27. David A. Morrow, Elliott M. Antman, Andrew Charlesworth et al. TIMI Risk Score for ST-Elevation Myocardial Infarction: A Convenient, Bedside, Clinical Score for Risk Assessment at Presentation, An Intravenous nPA for Treatment of Infarcting Myocardium Early II Trial Substudy. Circulation. 2000;102:20312037. $\quad$ https://doi.org/10.1161/01. CIR.102.17.2031.

Citation: Paudel N. Clinical Profile and Outcomes of Patients Undergoing Percutaneous Coronary Intervention: A 5 Year Experience. JCMS Nepal. 2021 ; 17(4); 308-15. 